\title{
ВОПРОСЫ ЗАКОННОСТИ И СПРАВЕДЛИВОСТИ РАСТОРЖЕНИЯ КОНТАКТА О СЛУЖБЕ В ТАМОЖЕННЫХ ОРГАНАХ РФ
}

Аннотация. Предметом проведенного исследования являются проблемы правовой регламентации порядка заключения контракта о службе в таможенных органах РФ, а также судебная практика по рассмотрению служебных споров, связанных с увольнением сотрудников таможенных органов со службы по окончанию срока контракта. Основное внимание уделяется вопросам заключения (незаключения) контракта о службе в таможенных органах на новый срок. В статье проанализированы обстоятельства, позволяющие сделать вывод о наличии широких пределов административного усмотрения начальников таможенных органов при реализации полномочий как по заключению контактов о службе в таможенных органах на новый срок, так и определению срока заключения контракта, которые, по мнению автора, способствуют активному проявлению субъективного фактора в служебных отношениях, могущее приводить к необоснованному и бесконтрольному увольнению сотрудников таможенных органов со службы. Методологическую основу написания статьи составили общенаучные (диалектический, анализ и синтез) и частные (формально-юридический, системно-структурный, сравнительно-правовой,) методы научного познания действительности. Аргументируется, что контрактная основа прохождения сотрудниками службы в таможенных органах не должна подразумевать произвольный подход к заключению контрактов и отсутствие единых и четких требований к условиям их заключения. Автор констатирует отсутствие положительной судебной практики по рассмотрению служебных споров по обжалованию увольнения сотрудников таможенных органов со службы по окончанию срока контракта, что, по мнению автора, требует особо пристального внимания к регламентации перезаключения контрактов. С точки зрения автора статьи наиболее серьезно увольнение со службы в таможенных органах затрагивает интересы и права сотрудниц таможенных органов, $c$ которыми не перезаключаются контракты на новый срок в период их нахождения в отпуске по беременности и родам либо по уходу за ребенком. Основным вкладом, который сделан автором в настоящей статье, является необходимость изменения правового регулирования порядка заключения контракта о службе в таможенных органах. Новизна статьи заключается в разработке предложений по определению порядка заключения контракта о службе в таможенных органах и увольнению со службы в таможенных органах по окончанию срока контракта, направленных на предотвращение текучести профессионального кадрового состава таможенных органов РФ.

Ключевые слова: таможенный орган, государственная служба, начальник таможенного органа, сотрудник, контракт, срок, суд, полномочия, увольнение, должность.

Abstract. The research subject is legal regulation of the procedure of conclusion of a contract on service in customs bodies and the judicial practice of consideration of official disputes connected with the termination of a labor contract. The main attention is paid to the problems of renewal (non-renewal) of a service contract. The paper analyzes the circumstances, demonstrating the broad limits of administrative discretion of the heads of customs bodies in the renewal of service contracts, which, in the author's opinion, lead to the intensification of a subjective factor in official relations and to the unjust and uncontrolled dismissals. The research methodology is based on general scientific methods (dialectics, analysis and synthesis) and specific ones (formal-legal, system-structural and comparative-legal). The author argues that the contract basis of service in customs bodies shouldn't allow for an unrestricted approach to the conditions of contracts conclusion and the absence of clear and precise requirements to the conditions of their conclusion. The author states the absence of a positive judicial practice of consideration of disputes over the appeal from the dismissal of customs bodies officers upon the service contract termination, therefore, in the author's opinion, it is necessary to pay particular attention to the regulation of contracts renewal. The author supposes that 
dismissal affects female officers, whose contracts are not renewed after their maternity leave, most of all. The author declares the necessity to regulate the procedure of conclusion of a service contract and develops the proposals about the establishment of a procedure of contract conclusion and dismissal, aimed at the prevention of turnover of the professional personnel in customs bodies of the Russian Federation.

Key words: term, contract, employee, head of a customs body, public service, customs body, court, authority, dismissal, post.

Aequum et bonum est lex legum - справедливость и благо - закон законов.

$\mathrm{B}$ последние годы распространенной категорией служебных споров стало обжалование сотрудниками таможенных органов РФ увольнения со службы в связи с истечением срока контракта. Положительная судебная практика отсутствует, независимо от фактических обстоятельств дел, подобные заявления в конечном счете остаются без удовлетворения. Данная статистика вполне объяснима, так окончание срока службы, предусмотренного контрактом, является самостоятельным основанием для увольнения со службы в таможенных органах РФ (пп. 4 п. 2 ст. 48 Федерального закона от 21.07.1997 № 114-ФЗ «0 службе в таможенных органах Российской Федерации») [1]. Кроме того, правовая оценка данной нормы закона была дана в Определении Конституционного Суда Российской Федерации от 20 октября 2005 года № $378-0$ «Об отказе в принятии к рассмотрению жалобы гражданина Климова Владимира Петровича на нарушение его конституционных прав пунктами 2 и 4 части первой статьи 77 Трудового кодекса Российской Федерации и пунктом 3 статьи 48 Федерального закона «0 службе в таможенных органах Российской Федерации», в котором указано, что правовая природа контракта, как акта, заключаемого на конкретный срок, предполагает, что регулируемые им правоотношения при наступлении определенной календарной даты (истечения срока) прекращаются. В итоге констатировано, что заключая контракт о службе в таможенных органах, гражданин тем самым соглашается и с тем, что по окончании предусмотренного контрактом срока его служба в таможенных органах будет прекращена [2]. Нельзя не отметить, что данная позиция была высказана Конституционным Судом Российской Федерации уже более десяти лет назад и судебная практика все это время остается стабильно отрицательной. Тем не менее обращения граждан в суд за защитой нарушенных, по их мнению, трудовых прав продолжаются. Что побуждает уволенных сотрудников таможенных органов в подобных условиях обращаться в суд? Анализируя судебную практику по данной категории служебных споров, можно констатировать, что основным лейтмотивом указанных обращений является стремление добиться справедливости, которая в ряде случаев, по сути, подменяется формальной буквой закона.

Служба в таможенных органах имеет контрактную основу, однако окончание срока контракта не всегда влечет прекращение служебных отношений. Так, согласно п. 5 статьи 10 Федерального закона «0 службе в таможенных органах Российской Федерации» контракт может быть заключен на новый срок по соглашению сторон до истечения срока его действия. Процедура заключения контракта на новый срок определена Положением о порядке заключения контракта о службе в таможенных органах Российской Федерации (далее - Положение) [3]. Согласно п. 19 Положения, не позднее чем за три месяца до истечения срока контракта сотрудник должен быть письменно предупрежден об истечении срока контракта и о возможном увольнении со службы в таможенных органах. Не позднее чем за два месяца до истечения срока действия контракта, при наличии заявления сотрудника о заключении контракта на новый срок руководитель структурного подразделения (начальник таможенного органа) направляет характеристику на данного сотрудника в кадровое подразделение таможенного органа, начальник которого уполномочен на заключение контракта с этим сотрудником. При этом в характеристике дается объективная оценка деловых и личных качеств сотрудника, указывается уровень профессиональной подготовки, знание законодательных и иных нормативных актов, регулирующих практическую деятельность сотрудника, результаты служебной деятельности, способность качественно решать возложенные на него задачи, а также предложения о заключении (незаключении) контракта на новый срок. Перед направлением характеристики в кадровый орган сотрудник должен быть ознакомлен с ее содержанием. Сотрудник вправе выразить свое несогласие с представленной характеристикой в письменной форме, приобщаемой к характеристике (п. 20 Положения).

Можно предположить, что условиями заключения контракта на новый срок является наличие заявления сотрудника таможенного органа о заключении контракта на новый срок, положительная характеристика руководителя структурного подразделения, содержащая предложение о заключении контракта с сотрудником на новый срок. Однако в действительности это не так. Согласно п. 21 Положения решение о заключении (незаклю- 


\section{Административное и муниципальное право 9 (105) • 2016}

чении) контракта с сотрудником на новый срок принимается начальником соответствующего таможенного органа, имеющим право назначения на соответствующую должность, с учетом представления не позднее чем за месяц до истечения срока контракта (руководителем ФТС России - не позднее чем за две недели). При решении о незаключении с сотрудником контракта на новый срок он должен быть предупрежден об увольнении со службы в таможенных органах в письменной форме не позднее чем за семь дней до дня истечения срока действия контракта. Получается, что заключение контракта на новый срок - это самостоятельное и исключительное право начальника соответствующего таможенного органа. И можно ли считать, что заключение контракта на новый срок осуществляется по соглашению сторон, если сотрудник желает продолжить службу в таможенных органах, что подтверждается его заявлением о заключении контракта на новый срок, а начальник таможенного органа ему в этом отказывает?

Отказывая в удовлетворении исковых заявлений о признании незаконными приказов об увольнении истцов со службы в таможенных органов в связи с окончанием срока контракта, суды обосновывают свои решения тем, что специальным законодательством, регулирующим порядок прохождения службы в таможенных органах, не установлена обязанность работодателя перезаключить с сотрудником контракт о службе в таможенных органах на новый срок и приводить мотивы отказа в заключении такого контракта. Возникает вопрос, пусть даже у работодателя нет установленной законом обязанности заключить контракт на новый срок, но какие у него есть фактические основания для его не заключения? Если сотрудник добросовестно работал, то почему с ним не может быть перезаключен контракт? Как известно, Федеральный закон «0 службе в таможенных органах Российской Федерации», так и Положение предусматривают возможность заключения контракта на новый срок, и это право реализуется на практике. Если должность не подлежит сокращению, а продолжает находиться в штатном расписании таможенного органа, то представляется важным выяснение в суде вопроса о том, почему с данным сотрудником не мог быть перезаключен контракт? В противном случае увольнение сотрудников таможенных органов по истечении срока контракта может превратиться в бесконтрольный и предвзятый механизм, что не должно иметь место на государственной службе.

Следует отметить, что закреплённую Положением процедуру увольнения сотрудников таможенных органов в связи с окончанием срока контракта нельзя считать четко и ясно определённой. Напри- мер, не определена форма принятия начальником таможенного органа решения о заключении (незаключении) контракта на новый срок, в связи с чем отсутствует и единообразная практика правового оформления такого решения: принятие отдельного правового акта, резолюция на представлении и т.д. Между тем суды довольно лояльно относятся к соблюдению данной процедуры. Например, в одном из судебных дел суд подчитал правомерным наличие характеристики, составленной руководителем подразделения не в рамках осуществления процедуры заключения (не заключения) контракта на новый срок, а за год до увольнения истицы в связи с присвоением ей очередного специального звания, что являлось, по мнению суда, объяснением тому факту, что она не была с ней ознакомлена [4]; в другом - отсутствие заблаговременного предупреждения об увольнении не было принято во внимание судом на том основании, что до истечения срока контракта истцом подано заявление о заключении контракта на новый срок [5] и т.п.

Обращает на себя внимание то обстоятельство, что суды в своих решениях цитируют п. 1 ст. 10 Федерального закона «0 службе в таможенных органах Российской Федерации», согласно которому контракт о службе в таможенных органах заключается в письменной форме между гражданином и соответствующим таможенным органом в лице его начальника на срок один, три года, пять или десять лет, а также до достижения гражданином предельного возраста пребывания на службе в таможенных органах с соблюдением требований настоящего Федерального закона. В тоже время, законодатель, установив возможные сроки контракта, не оговорил условия или случаи, когда контракт заключается на один, три года, пять или десять лет. Отсутствуют они и в Положении. Как показывает практика, контракты о службе в таможенных органах стали заключаться в основном на один год, по истечении которого начальник таможенного органа имеет право немотивированно и безапелляционно отказать в перезаключении контракта и уволить сотрудника, тогда о какой стабильности правового положения сотрудника, повышении его профессионализма и ответственности, в данных обстоятельствах можно вести речь! Организация кадровой политики таможенных органов в подобных условиях видится весьма непонятной, и это при всем при том, что каждый сотрудник проходит первоначальную подготовку, систематическое повышение квалификации, стажировки и т.д. При чем данная ситуация выглядит не логичной как в отношении гражданина, впервые поступившего на службу в таможенные органы, так и сотрудника за плечами которого длительный опыт добросовестной и безупречной службы! В указанном 
контексте заслуживает внимание сомнения ряда специалистов о необходимости существования на государственной службе в принципе договора как основы взаимоотношений между государственными служащими и государством как таковым или его органом. Например, ведущий специалист в области государственной службы А.А. Гришковец вопросы юридического оформления приобретения полномочий государственного служащего, назначения на должность и освобождения от должности ставит в неразрывную связь с обеспечением реальной стабилизации правового положения государственного служащего, предлагая поступление на государственную службу осуществлять на конкурной основе и юридически оформлять актами Президента РФ или Правительства РФ [6, с. 58]. Подобные научные предложения, имеющие весьма серьезную аргументацию, заставляют поставить под сомнение незыблемость существование на государственной службе контрактного механизма. Насколько обоснована, объективно необходима и соответствует потребностям службы в таможенных органах существующая в настоящее время система заключения срочных служебных контрактов, приводящая к текучести хорошо обученного кадрового состава, к систематическим судебным спорам о восстановлении на работе?? В условиях отсутствия нормативно установленных оснований для перезаключения контракта, возможность прекращения служебных отношений в связи с окончанием срока контракта становится своеобразным «дамокловым мечом» службы в таможенных органах. Между тем контрактная основа прохождения сотрудниками службы в таможенных органах не должна подразумевать произвольный подход к заключению контрактов и отсутствие единых и четких требований к условиям их заключения [7, с. 47-49; 8, с. 108-111].

На основании вышеизложенного можно сделать вывод о наличии широких пределов административного усмотрения начальников таможенных органов при реализации полномочий как по заключению контактов о службе в таможенных органах на новый срок, так и определению срока заключения контракта. Вместе с тем следует учитывать, что широта дискреционных полномочий должностных лиц является одним из коррупциогенных факторов [9]. В связи с этим многие специалисты важнейшим средством совершенствования реализации административно-правовых средств предупреждения и пресечения коррупции видят избавление от дискреционных полномочий должностных лиц. Разделяя в целом данный подход, следует учитывать, что административное усмотрение предполагает свободу усмотрения уполномоченного лица в рамках определённых законом, при этом имеет значительный положительный потенциал в исполнительно-распорядительной деятельности органов исполнительной власти, выступая «одушевляющим импульсом многих юридических действий и решений» [10, с. 62], а в ряде случаях «необходимым условием принятия обоснованного и справедливого решения» $[11$, с. 8]. Поэтому представляется справедливым утверждение, что «дискреционные полномочия становится фактором, провоцирующим ненадлежащее (в том числе и коррупционное) поведение уполномоченного лица в том случае, когда нечетко определены его границы и отсутствуют критерии его принятия, поэтому речь должна идти не о радикальной элиминации правоприменительной дискреции, а о разработке и нормативном закреплении критериев надлежащего осуществления таких полномочий» [12, с. 313-314]. В связи с этим представляется необходимым установить законодательные пределы административного усмотрения начальников таможенных органов при заключении контрактов о службе в таможенных органах, а именно определить основания заключения (незаключения) контракта на новый срок, а также дифференцировать условия заключения контракта на предусмотренные законодателем возможные сроки его заключения.

Представляется, что наиболее серьезно увольнение со службы в таможенных органах затрагивает интересы и права сотрудниц таможенных органов, с которыми не перезаключаются контракты на новый срок в период их нахождения в отпуске по беременности и родам либо по уходу за ребенком. Вряд ли выглядит справедливой ситуация, когда сотрудница, добросовестно служившая в таможенных органах на благо государства, уходит в декретный отпуск, а с ней расторгается служебный контракт за истечением его срока. Имея на руках малолетнего ребенка, она оказывается и без работы, а значит гарантированного заработка, и без ежемесячного пособия на ребенка, полагающегося ей с учетом стажа службы. В этом контексте хотелось бы привести в качестве примера одно судебное дело, инициированное уволенной сотрудницей таможенных органов в период отпуска по уходу за ребенком, не достигшим возраста 1,5 лет. В своем исковом заявлении о признании незаконным отказа в заключении с ней контракта о службе в таможенных органах и восстановлении на службе, она указала, что является одинокой матерью, воспитывающей двух несовершеннолетних детей. Суд оставил исковые требования без удовлетворения, констатировав, что «каких-либо исключений, устанавливающих невозможность прекратить служебные отношения в связи с истечение срока действия контракта, законом не установлено» [13; 


\section{Административное и муниципальное право 9 (105) • 2016}

14]. На довольно жесткую позицию судов указывает и тот факт, что суд первой инстанции не удовлетворил ходатайство истицы о восстановлении срока подачи иска о восстановлении на службе, хотя она указывала на грубейшие нарушения процедуры увольнения: с приказом об увольнении не ознакомлена, об увольнении узнала в телефонном режиме, трудовая книжка не выдана. При этом суд апелляционной инстанции также подтвердил, «что доказательств уважительности причин пропуска срока обращения в суд, не представлено. Обстоятельств, объективно препятствующих обратиться в суд в установленный законом срок, не установлено» [15].

Не менее показательным является судебное дело об увольнении сотрудницы таможенных органов в связи с окончанием срока контракта во время нахождения ей в отпуске по беременности и родам. При этом в вину истицы был поставлен тот факт, что доказательств, препятствующих заявительнице своевременно обратиться к ответчику с заявлением о продлении контракта ей не представлено. И это при том, что сам таможенный орган не выполнил надлежащим образом ни обязанность по извещению сотрудницы об истечении срока контракта и о возможности ее увольнения со службы в таможенных органах, ни по извещению о прекращении срока действия контракта и принятом решении начальника таможенного органа о незаключении с ней контракта на новый срок и увольнении со службы в таможенных органах [16].

Трудовой кодекс РФ включает статью 261 Трудового кодекса РФ, которая предоставляет повышенные гарантии беременной женщине и лицам с семейными обязанностями при расторжении трудового договора. По своей сути она является трудовой льготой, направленной на обеспечение материнства и детства в соответствии с ч. 2 ст. 7 и ч. 1 ст. 38 Конституции Российской Федерации. К сожалению, для женщин, которые проходят государственную службу, гарантии, связанные с материнством и воспитанием детей, не установлены. Тем не менее существует возможность применения норм Трудового кодекса РФ к государственной гражданской службе. Согласно статьи 79 Федерального закона от 27 июля 2004 № 79-ФЗ «0 государственной гражданской службе Российской Федерации» федеральные законы, иные нормативные правовые акты Российской Федерации, законы и иные нормативные правовые акты субъектов Российской Федерации, содержащие нормы трудового права, применяются к отношениям, связанным с гражданской службой, в части, не урегулированной настоящим Федеральным законом [17]. К примеру, истицы обратились в суд с иском к таможенному органу о признании незаконным их увольнения в период отпуска по уходу за ребенком вследствие реорганизации таможни, в которой они проходили государственную гражданскую службу, по п. 6 ч. 1 ст. 33 Федерального закона «0 государственной гражданской службе Российской Федерации» (отказ государственного служащего от предложенной для замещения иной должности гражданской службы либо профессиональной переподготовки или повышения квалификации в связи с сокращением должностей гражданской службы, а также при непредставлении ему в этих случаях иной должности гражданской службы»). В частности, они указывали на нарушение представителем нанимателя ч. 4 статьи 261 Трудового кодекса РФ, согласно которой расторжение трудового договора с женщиной, имеющей ребенка в возрасте до трех лет, с одинокой матерью, воспитывающей ребенка-инвалида в возрасте до восемнадцати лет или малолетнего ребенка - ребенка в возрасте до четырнадцати лет, с другим лицом, воспитывающим указанных детей без матери, с родителем (иным законным представителем ребенка), являющимся единственным кормильцем ребенка-инвалида в возрасте до восемнадцати лет либо единственным кормильцем ребенка в возрасте до трех лет в семье, воспитывающей трех и более малолетних детей, если другой родитель (иной законный представитель ребенка) не состоит в трудовых отношениях, по инициативе работодателя не допускается, за исключением случаев, установленных Трудовым кодексом РФ. Приходя к выводу о незаконности увольнения истиц, суд сделал вывод, что увольнение гражданских служащих по указанному основанию не может осуществляться без предоставления гарантий, предусмотренных для случаев расторжения служебного контракта по инициативе представителя нанимателя, в частности, гарантий, предусмотренных ч. 4 ст. 261 Трудового кодекса РФ, так как «положений, исключающих предоставление гарантий, которые установлены законодательством Российской Федерации для женщин в связи с рождением и воспитанием детей, законодательство о государственной гражданской службе Российской Федерации не содержит» [18; 19]. С точностью до наоборот меняется ситуация в случае, когда идет речь о расторжении контракта о службе в таможенных органах. Суды напротив указывают, что ссылка на статью 261 Трудового кодекса РФ неправомерна, поскольку его нормы в данном случае применяются только к отношениям, не урегулированным Федеральным законом «0 службе в таможенных органах Российской Федерации» [20].

Вместе с тем, давать оценку сложившейся судебной практике по увольнению сотрудниц таможенных органов в период их нахождения в отпуске 
по беременности и родам либо по уходу за ребенком необходимо прежде всего с позиции защиты материнства и детства. Разделяем позицию о том, что отношение к материнству в обществе должно быть особенным, не только внимательным - трепетным! Если люди думают о своём будущем, если они не хотят вырождения и гибели своего народа, они обязаны возвести материнство в священный культ [21]. Представляется, что, прежде всего, это должно стать призывом к законодателю. Необходимо предоставить гарантии лицам от увольнения с государственной службы в период, когда они находятся в отпуске по беременности и родам или по уходу за ребенком. Уместно добавить, что данные гарантии следует предоставить не только женщинам, так как в силу разных обстоятельств в отпуске по уходу за ребенком могут находиться и мужчины [22]. Однако данный призыв следует адресовать и судьям, рассматривающим судебные дела по искам государственных служащих о восстановлении на службе, которые должны обеспечить надлежащую судебную защиту государственного служащего как более слабой стороны в служебных спорах, связанных с его увольнением, тем более, когда речь идет об увольнении женщины, ухаживающей за малолетним ребенком.

Следует отметить, что зачастую судебные решения по спорам о защите нарушенных прав в связи с увольнением сотрудников таможенных органов в связи с истечением контракта содержат выводы, взятые из определения Конституционного Суда РФ от 11.05.2012 № 700-0 [23], вынесенного по жалобе гражданки Зеленовой Ю.Н., уволенной с государственной гражданской службы в связи с истечением срока действия срочного служебного контракта. Нарушение своих прав заявительница усматривала в том, что оспариваемые положения закона в их взаимосвязи не относят увольнение в связи с истечением срока действия срочного служебного контракта к основаниям увольнения по инициативе представителя нанимателя, что позволяет ему расторгнуть по данному основанию срочный контракт с государственным гражданским служащим - женщиной, находящейся в отпуске по уходу за ребенком до достижения им возраста полутора лет. Конституционный Суд Российской Федерации отказал в принятии к рассмотрению данной жалобы, указав при этом, что гражданин, давая согласие на заключение служебного контракта на определенный срок в установленных законодательством случаях, знает о его прекращении по истечении заранее оговоренного временного периода и соглашается на прохождение государственной гражданской службы на оговоренных в служебном контракте условиях. При этом истечение срока действия срочного служебного контрак- та является объективным событием, наступление которого не зависит от воли представителя нанимателя, а потому увольнение государственного гражданского служащего по данному основанию отнесено к общим основаниям прекращения служебного контракта. Такое правовое регулирование, констатировал суд, не может рассматриваться как нарушающее права государственных гражданских служащих, в том числе принцип равенства, поскольку в равной мере распространяется на всех государственных гражданских служащих, замещающих должности на основании срочного служебного контракта.

При этом данные выводы Конституционный Суд Российской Федерации сделал применительно не только к государственной гражданской службе, указав, что аналогичное правовое регулирование действует в отношении лиц, заключивших срочный трудовой договор, что позволяет судам распространять их на правоотношения, связанные с заключением контрактов о службе в таможенных органах. Однако в этой мотивировке снова остается без правовой оценки следующие нормы закона. Вопервых, о том, что с сотрудником изначально возможно заключение контракта не на год, а на более длительный срок. Реализуется ли в данном случае принцип равенства, если в отсутствие установленных нормативных оснований для дифференциации временного периода заключения контракта, с одним сотрудником заключается контракт на год, с другим - на три, с третьим - на пять, а с четвертным - сразу на десять лет?! Во-вторых, законодатель все же предусматривает возможность перезаключить контракт. Реализуется ли в данном случае принцип равенства, если с одним сотрудником по истечении срока контракта служебные отношения прекращаются, а с другим продлеваются и заключается контракт на новый срок?! В-третьих, уместно ли говорить о равенстве государственных служащих в случае, если речь идет о женщине, находящейся к моменту истечения срока действия контракта в отпуске по беременности и родам или по уходу за ребенком!?

Хотелось также добавить, что в вышеуказанном определении Конституционный Суд Российской Федерации указал, что «разрешение же вопроса о распространении на государственных гражданских служащих, увольняемых в связи с истечением срока действия срочного служебного контракта, гарантий, предоставляемых государственным гражданским служащим при расторжении служебного контракта по инициативе представителя нанимателя, связано с внесением изменений в действующее законодательство и к компетенции Конституционного Суда Российской Федерации не относится». Однако до сих пор за- 
конодательство о государственной гражданской службе в этой части осталось без изменения.

На основании вышеизложенного представляется необходимым внести следующие изменения и дополнения в Федеральный закон «О службе в таможенных органах Российской Федерации»: 1) установить условия заключения контракта о службе в таможенных органах на один, три, пять и десять лет; 2) установить основания заключения (незаключения) контракта на новый срок; 3) внести изменения в п. 2 ст. 48 закона, закрепив, что сотрудник таможенного органа может быть уволен со службы в таможенных органах по окончании срока службы, предусмотренного контрактом, за исключением случаев нахождения его в отпуске по беременности и родам или по уходу за ребенком до достижения возраста трех лет, при наличии заявления сотрудника о заключении контракта на новый срок.

\section{Библиография:}

1. Федеральный закон от 21.07.1997 N 114-Ф3 «0 службе в таможенных органах Российской Федерации» // "Собрание законодательства РФ", 28.07.1997, N 30, ст. 3586.

2. Определение Конституционного Суда Российской Федерации от 20 октября 2005 года № 378-0 «0б отказе в принятии к рассмотрению жалобы гражданина Климова Владимира Петровича на нарушение его конституционных прав пунктами 2 и 4 части первой статьи 77 Трудового кодекса Российской Федерации и пунктом 3 статьи 48 Федерального закона «О службе в таможенных органах Российской Федерации» // Документ опубликован не был // СПС «КонсультантПлюс»

3. Приказ ФТС России от 01.12.2008 № 1504 (ред. от 18.02.2013) «Об утверждении Положения о порядке заключения контракта о службе в таможенных органах Российской Федерации и типовой формы контракта о службе в таможенных органах Российской Федерации» // "Российская газета", N 55, 01.04.2009.

4. Определение Московского городского суда от 28.04.2011 по делу N 33-12694// СПС «КонсультантПлюс».

5. Апелляционное определение Московского областного суда от 17.07.2013 по делу N 33-14118/2013 // СПС «КонсультантПлюс»

6. Гришковец А.А. Правовое регулирование государственной гражданской службы в Российской Федерации: Учебный курс, М.: Издательство «Дело и сервис», 2003. С. 58.

7. Трунина Е.В. Контрактная основа службы в таможенных органах: вопросы защиты прав сотрудников от субъективизма работодателей // Современное право. 2012. N 12. С. 47-49.

8. Трунина Е.В. Правоохранительная и гражданская службы в таможенных органах Российской Федерации (проблемы совершенствования): монография. Волгоград, 2011. С. 108-111.

9. Постановление Правительства РФ от 26.02.2010 № 96 «Об антикорупциогенной экспертизе нормативных правовых актов и проектов нормативных правовых актов» // "Российская газета", N 46, 05.03.2010.

10. Тихомиров Ю.А. Административное усмотрение и право // Журнал российского права. 2000. N 4. С. 62.

11. Братановский С.Н. Государственное управление: понятие и социальная сущность // Вестник ЕАAН. 2011. N 6. C. 8.

12. Братановский С.Н., Зеленов М.Ф. Дискреционные полномочия как фактор коррупции в системе исполнительной власти // Административное и муниципальное право. 2016. N 4. C. 313-314. DOI:10.7256/1999-2807.2016.4.16725. URL: http://www.nbpublish.com/library_show_article.php?id_article=36805.

13. Решение Пролетарского районного суда г. Ростов-на-Дону от 04.03.2012 // СПС «КонсультантПлюс.

14. Апелляционное определение от 16.05. 2013 по делу N 33-5076 // СПС «КонсультантПлюс.

15. Апелляционное определение Ростовского областного суда от 16.05.2013 по делу N 33-5076// СПС «КонсультантПлюс».

16. Определение Санкт-Петербургского городского суда от 15.07.2009 N 9662 // СПС «КонсультантПлюс».

17. Федеральный закон от 27.07.2004 N 79-ФЗ (ред. от 30.12.2015) "О государственной гражданской службе Российской Федерации" // "Российская газета", N 162, 31.07.2004.

18. Апелляционное определение Костромского областного суда от 08.05.2013 по делу N 33-726 // СПС «КонсультантПлюс».

19. Апелляционное определение Омского областного суда от 19.07.2013 по делу N 33-3735/2013 // СПС «КонсультантПлюс».

20. Определение Московского городского суда от 28.04.2011 по делу N 33-12694// СПС «КонсультантПлюс».

21. Щёголев A. А. Материнство [Электронный ресурc]. URL: http://докторщёголев.pф/lib/moms.

22. Кассационное определение Волгоградского областного суда от 08.02.2012 по делу N 33-1482/2012// СПС «КонсультантПлюс».

23. Определение Конституционного Суда РФ от 11.05.2012 № 700-0 «Об отказе в принятии к рассмотрению жалобы гражданки Зеленовой Юлии Николаевны на нарушение ее конституционных прав пунктом 2 части 1 статьи 33, частью 1 статьи 35, частями 1 и 3 статьи 37 Федерального закона "О государственной гражданской службе Российской Федерации» // СПС «КонсультантПлюс».

\section{References (transliterated):}

1. Federal'nyi zakon ot 21.07.1997 N 114-FZ «O sluzhbe v tamozhennykh organakh Rossiiskoi Federatsii» // "Sobranie zakonodatel'stva RF", 28.07.1997, N 30, st. 3586. 
2. Opredelenie Konstitutsionnogo Suda Rossiiskoi Federatsii ot 20 oktyabrya 2005 goda № 378-0 «Ob otkaze v prinyatii k rassmotreniyu zhaloby grazhdanina Klimova Vladimira Petrovicha na narushenie ego konstitutsionnykh prav punktami 2 i 4 chasti pervoi stat'i 77 Trudovogo kodeksa Rossiiskoi Federatsii i punktom 3 stat'i 48 Federal'nogo zakona «0 sluzhbe v tamozhennykh organakh Rossiiskoi Federatsii» // Dokument opublikovan ne byl // SPS «Konsul'tantPlyus»

3. Prikaz FTS Rossii ot 01.12.2008 № 1504 (red. ot 18.02.2013) «Ob utverzhdenii Polozheniya o poryadke zaklyucheniya kontrakta o sluzhbe v tamozhennykh organakh Rossiiskoi Federatsii i tipovoi formy kontrakta o sluzhbe v tamozhennykh organakh Rossiiskoi Federatsii» // "Rossiiskaya gazeta", N 55, 01.04.2009.

4. Opredelenie Moskovskogo gorodskogo suda ot 28.04.2011 po delu N 33-12694// SPS «Konsul'tantPlyus».

5. Apellyatsionnoe opredelenie Moskovskogo oblastnogo suda ot 17.07.2013 po delu N 33-14118/2013 // SPS «Konsul'tantPlyus»

6. Grishkovets A.A. Pravovoe regulirovanie gosudarstvennoi grazhdanskoi sluzhby v Rossiiskoi Federatsii: Uchebnyi kurs, M.: Izdatel'stvo «Delo i servis», 2003. S. 58.

7. Trunina E.V. Kontraktnaya osnova sluzhby v tamozhennykh organakh: voprosy zashchity prav sotrudnikov ot sub"ektivizma rabotodatelei // Sovremennoe pravo. 2012. N 12. S. 47-49.

8. Trunina E.V. Pravookhranitel'naya i grazhdanskaya sluzhby v tamozhennykh organakh Rossiiskoi Federatsii (problemy sovershenstvovaniya): monografiya. Volgograd, 2011. S. 108-111.

9. Postanovlenie Pravitel'stva RF ot 26.02.2010 № 96 «Ob antikoruptsiogennoi ekspertize normativnykh pravovykh aktov i proektov normativnykh pravovykh aktov» // "Rossiiskaya gazeta", N 46, 05.03.2010.

10. Tikhomirov Yu.A. Administrativnoe usmotrenie i pravo // Zhurnal rossiiskogo prava. 2000. N 4. S. 62.

11. Bratanovskii S.N. Gosudarstvennoe upravlenie: ponyatie i sotsial'naya sushchnost' // Vestnik EAAN. 2011. N 6. S. 8.

12. Bratanovskii S.N., Zelenov M.F. Diskretsionnye polnomochiya kak faktor korruptsii v sisteme ispolnitel'noi vlasti // Administrativnoe i munitsipal'noe pravo. 2016. N 4. S. 313-314. DOI:10.7256/1999-2807.2016.4.16725. URL: http:// www.nbpublish.com/library_show_article.php?id_article=36805.

13. Reshenie Proletarskogo raionnogo suda g. Rostov-na-Donu ot 04.03.2012 // SPS «Konsul'tantPlyus.

14. Apellyatsionnoe opredelenie ot 16.05. 2013 po delu N 33-5076 // SPS «Konsul'tantPlyus.

15. Apellyatsionnoe opredelenie Rostovskogo oblastnogo suda ot 16.05.2013 po delu N 33-5076// SPS «Konsul'tantPlyus».

16. Opredelenie Sankt-Peterburgskogo gorodskogo suda ot 15.07.2009 N 9662 // SPS «Konsul'tantPlyus».

17. Federal'nyi zakon ot 27.07.2004 N 79-FZ (red. ot 30.12.2015) "O gosudarstvennoi grazhdanskoi sluzhbe Rossiiskoi Federatsii" // "Rossiiskaya gazeta", N 162, 31.07.2004.

18. Apellyatsionnoe opredelenie Kostromskogo oblastnogo suda ot 08.05.2013 po delu N 33-726 // SPS «Konsul'tantPlyus».

19. Apellyatsionnoe opredelenie Omskogo oblastnogo suda ot 19.07.2013 po delu N 33-3735/2013 //SPS «Konsul'tantPlyus».

20. Opredelenie Moskovskogo gorodskogo suda ot 28.04.2011 po delu N 33-12694// SPS «Konsul'tantPlyus».

21. Shchegolev A. A. Materinstvo [Elektronnyi resurs]. URL: http://doktorshchegolev.rf/lib/moms.

22. Kassatsionnoe opredelenie Volgogradskogo oblastnogo suda ot 08.02.2012 po delu N 33-1482/2012// SPS «Konsul'tantPlyus».

23. Opredelenie Konstitutsionnogo Suda RF ot 11.05 .2012 № 700-O «Ob otkaze v prinyatii k rassmotreniyu zhaloby grazhdanki Zelenovoi Yulii Nikolaevny na narushenie ee konstitutsionnykh prav punktom 2 chasti 1 stat'i 33, chast'yu 1 stat'i 35, chastyami 1 i 3 stat'i 37 Federal'nogo zakona "O gosudarstvennoi grazhdanskoi sluzhbe Rossiiskoi Federatsii» // SPS «Konsul'tantPlyus». 